EXAMPLE USING TRAVERSE TABLE

The $5228 \mathrm{ft}$. peak of the island Anjouan was observed from m.v. British Willow in a D.R. position 60 miles off. The height of eye was $56 \mathrm{ft}$. and the sextant angle read $28: 8$

Index error on the arc:

0 :8 Height of peak

$28: 0$

Dip

Refraction $(60 \div 12)$

True angle of elevation

From traverse table

under $12^{\circ}$

under $\mathrm{I}^{\circ}{ }^{\circ}$

Interpolating
$7 \cdot 3$

$20: 7$

$5: 0 \quad h$

Height of eye

$56 \mathrm{ft}$.

$5172 \mathrm{ft}$.

I 5.7 From table $1 \cdot 06 \sqrt{ } h=\mathbf{7 6 \cdot 2}$ n.m.

$\begin{array}{lll}\text { Distance } & \text { D. Lat } & \text { Dep } \\ 77.9 & 76.2 & 16.2 \\ 77.6 & 76.2 & 14.8 \\ 77.8 & 76.2 & 15.7 \\ 15.7 & & \end{array}$

$62 \cdot$ I n.m.

True distance off

It should be noted that the interpolation required in the traverse table is that carried out by ocean navigators when calculating currents.

\title{
Captain Mário Gama's Direct Method for Star-sight Reduction
}

\section{Charles H. Cotter}

IN a very interesting paper which appeared recently1 the author, Capitão Mário Gama of the Portuguese Merchant Navy, describes a direct method for computing position lines from star (or planet) observations.

The principal feature of Captain Gama's method is the systematic manner in which he arrives at an intercept to the extent, not only of saving time in sight reduction, but also in reducing the possibility of blundering.

The method employs the Computed Tables of Altitude and Azimuth (HD 486) and involves timing a series of star-sights, the ship making headway meanwhile, by means of a stop watch which is set at zero at a noted chronometer time shortly before the observations commence. The following example, given in the original paper, in reducing sights of Vega and Denebola observed during morning twilight of 25 Feb. 1959 , in D.R. position Lat. $10^{\circ} 10^{\prime}$ S., Long. $73^{\circ} 48^{\prime}$ E., will serve to illustrate the method. 


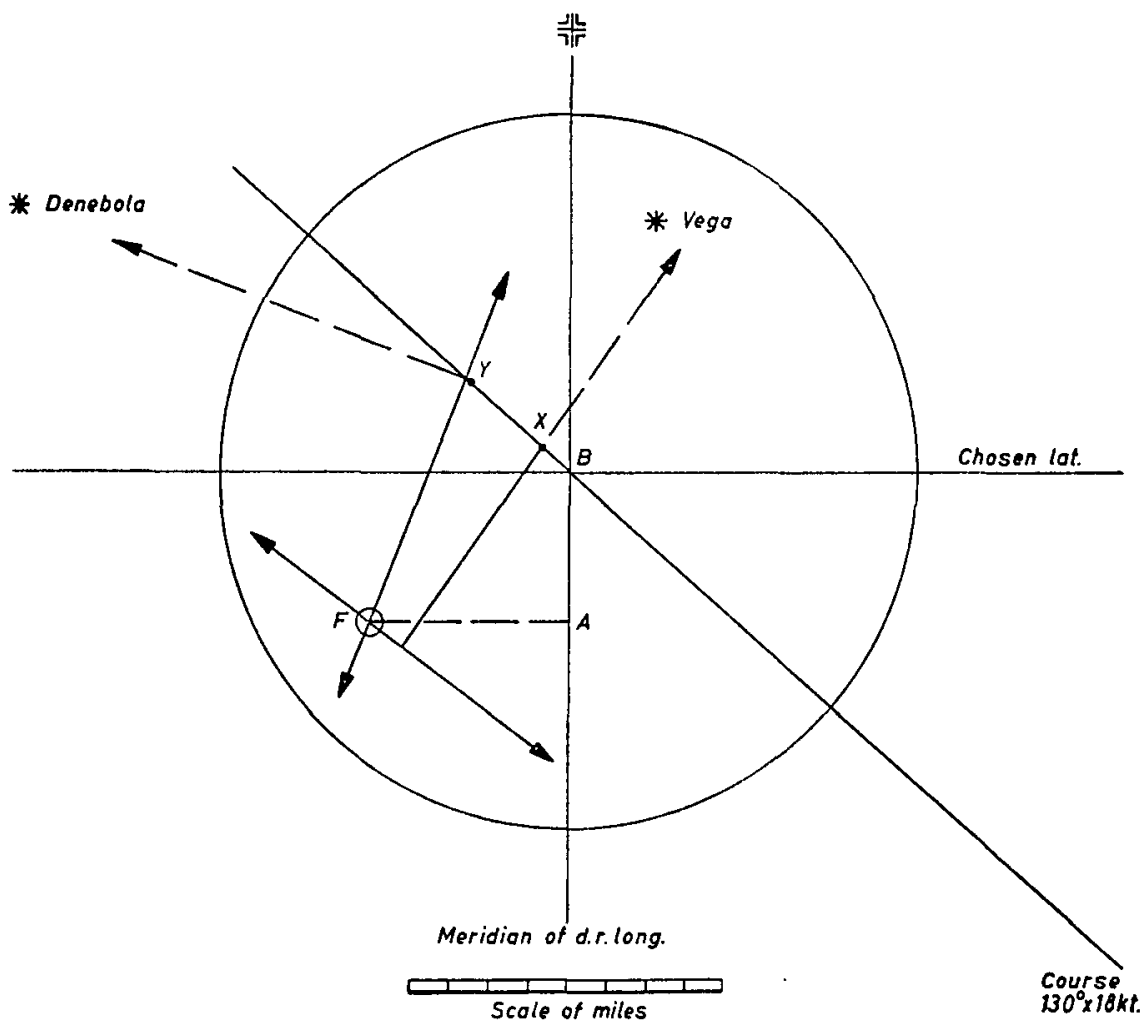

FIG. I. Method for finding the ship's observed position for the time at which the stop watch was started.

\section{Data}

Height of eye

Index Error and Dip

Chosen Lat.

Chron. Time

Chron. Error

G.M.T.

G.H.A. $r$ o ${ }^{\mathrm{h}}$

Increment

G.H.A. $\uparrow$ oo $3^{8^{\mathrm{m}}} 4^{\mathrm{s}}$

Chosen Long.

L.H.A. $r$

Course and Speed
$32 \mathrm{ft}$.

$-7 \cdot 2$

$10^{\circ} \mathrm{S}$.

$00^{\mathrm{h}} 3^{\mathrm{m}} \quad 2 \mathrm{I}^{\mathrm{s}}$

Slow

2 I $^{3}$

(25)

$00^{\mathrm{h}} 3^{8^{\mathrm{m}}} 4^{\mathrm{s}}$

$154^{\circ} 06.6$

$9^{\circ} 4^{2 \cdot 1}$

$163^{\circ} 48 \cdot 7$

$73^{\circ} 48 \cdot \circ$ E. (+)

$237^{\circ} 36 \cdot 7$

$130^{\circ}(\mathrm{T}) \times 18$ knots 


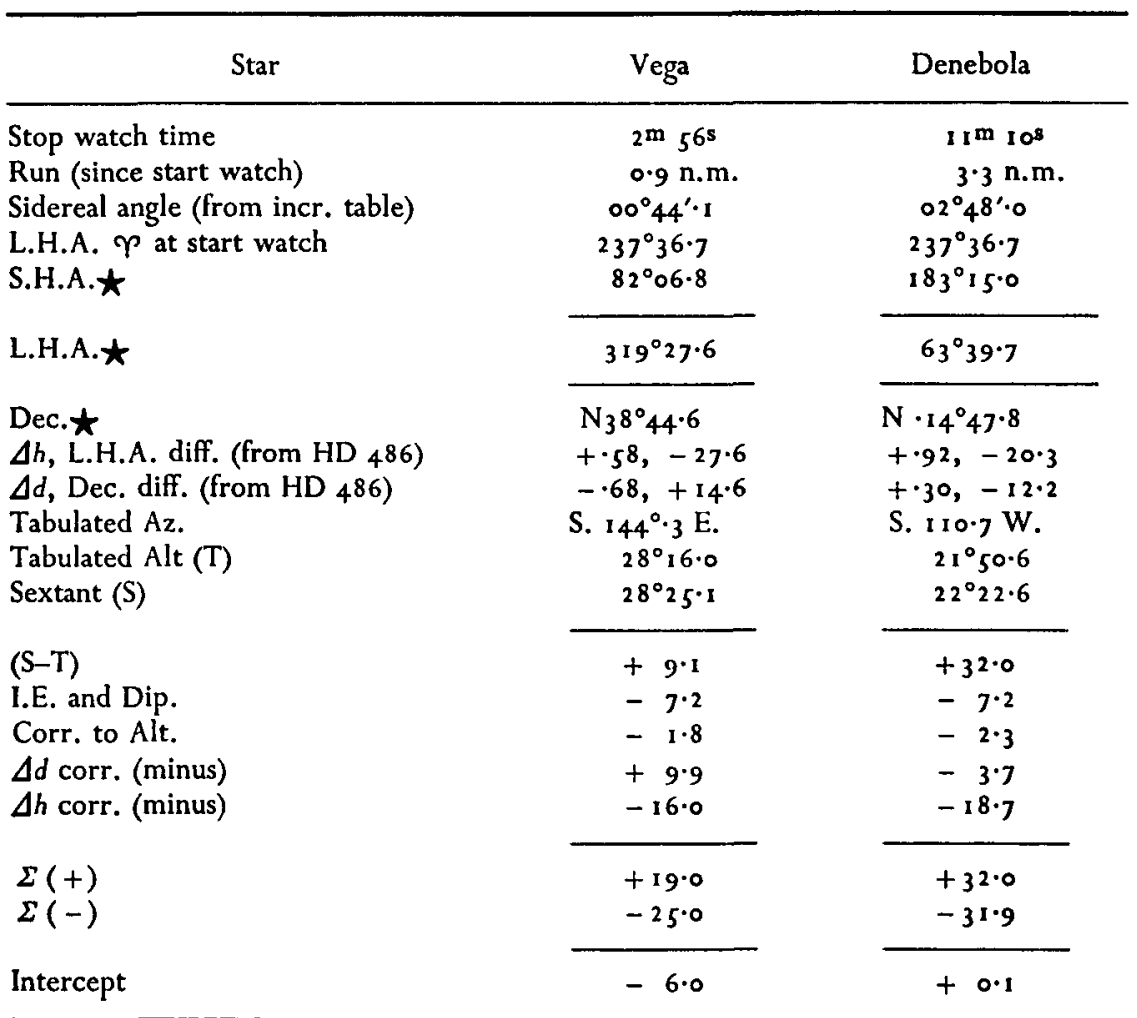

From $035^{\circ} \cdot 7$

To $290^{\circ} \cdot 7$

By means of a plotting sheet on which the centre of a printed compass rose represents the chosen position (nearest integral degree of latitude to D.R latitude and D.R. longitude), it is a simple matter to find the ship's observed position for the time at which the stop watch (initially set to $00^{\mathrm{m}} 00^{\mathrm{s}}$ ) was started.

$$
\begin{aligned}
& \text { Lat. } B=10^{\circ} 00^{\prime} \mathrm{S} \text { Long. } B \quad 73^{\circ} 4^{\prime} \mathrm{E} \text {. } \\
& \text { dlat }(A B)=\quad 4^{\prime} \mathrm{S} \text {. dlong (AF) } \quad 5^{\prime} \mathrm{W} .(\operatorname{dep}(A F)=5 \mathrm{~m} . \mathrm{n}) \text {. } \\
& \text { Lat. } \mathrm{F}=\overline{10^{\circ} 04^{\prime} \mathrm{S} .} \quad \text { Long. } \mathrm{F} \quad \overline{73^{\circ} 43^{\prime} \mathrm{E} \text {. }}
\end{aligned}
$$

The points $X$ and $Y$ are marked at distances respectively of 0.9 n.m. and 3.3 n.m. (the corresponding distances run in the intervals between the times at which the stop watch was started and the observations made), in a direction opposite to that of the heading $\left(130^{\circ} \mathrm{T}\right.$.) of the ship. Using these points from which to mark the corresponding intercepts, and hence the position lines, the intersection of the latter at $F$ represents the observed position of the ship at the time the stop watch was started.

The same chosen position is used for each sight of a series, and the L.H.A. of each star, used in determining the tabulated altitudes, applies to a common 
L.H.A. $\uparrow$, which latter corresponds to the time at which the stop watch was started.

The author of this interesting method is to be congratulated for his systematic and thoroughly seamanlike solution.

\section{R EFER EN CE}

1 Método directo para o cãlculo do ponto astronómico por observacão de Estrelas ou Planetas. Mário Gama, Capitão da Marinha Mercante. (Neptuno: Revista da Marinha Mercante Nacional, No. 211 , Jan./Mar. 1969, 42-54.)

\section{Amendments to the Rules}

\section{A. N. Cockcroft}

A GREAT deal has already been written about possible amendments to the Collision Regulations, but as there may be an international conference on the subject in 1972 the various schemes should be discussed as much as possible so that their advantages and disadvantages will be fully appreciated.

Criticism of the present Steering and Sailing Rules is mainly concerned with Rule $2 \mathrm{I}$. Disadvantages of this rule include the following:

(1) If a giving-way vessel on a crossing course takes no action the privileged vessel must not act until collision cannot be avoided by the giving-way vessel alone. By such time collision is likely to be inevitable.

(2) Small sailing vessels which may not easily be seen, especially at night, are required to maintain course and speed for large power-driven vessels.

(3) High-speed vessels such as hovercraft are required to maintain course and speed for low powered ships crossing from the port side.

(4) No provision is made for different types of hampered vessel approaching one another so as to involve risk of collision. If deep-draught vessels in certain areas are to be included in this category in the future the question of priorities may have to be considered.

(5) An ordinary power-driven vessel is not permitted to give way to a tow on the port bow. In certain circumstances a tow is permitted to show the lights and shapes for a vessel not under command, though this is not generally appreciated.

(6) A vessel being overtaken is apparently always required to keep her course and speed even though some hampered vessels carrying out special operations at high speeds may be unable to take action to keep clear.

(7) Rule 2 I can only apply to vessels in visual sight of one another. Any rules or guidance for vessels using radar in fog could not be consistent with the present Steering and Sailing Rules.

Rule 16 and the Annex are criticized mainly on the grounds that there is insufficient instruction or guidance for a vessel using radar in fog. Such a vessel 